\title{
Direct labelling of ipratropium bromide aerosol and its deposition pattern in normal subjects and patients with chronic bronchitis
}

\author{
STEPHEN G SPIRO, CAROLLE A SINGH, SUSAN EJ TOLFREE, \\ MARTYN R PARTRIDGE, MICHAEL D SHORT
}

From the Departments of Respiratory Medicine and Medical Physics and Bioengineering, University College Hospital, London

ABSTRACT A technique for the direct labelling of ipratropium bromide with bromine-77, with reconstitution of the drug in a metered dose inhaler so as to be identical to the commercial product, was used to study drug deposition patterns in seven normal subjects and seven patients with chronic bronchitis (mean $\mathrm{FEV}_{1} 32 \%$ (SD 12.2\%) predicted normal). The gamma camera image of the thorax was divided into a middle zone - the mediastinal zone-and the lung itself into a central zone comprising its medial third and a peripheal zone, the lateral two thirds. Measurements after 10 inhalations of labelled ipratropium bromide showed similar results for the two groups of subjects. The total lung dose inhaled was $11.2 \%$ of $203 \mu \mathrm{g}$ and $11.7 \%$ of $186 \mu \mathrm{g}$ in the normal subjects and the patients respectively. In contrast to the deposition patterns seen in aerosol studies using steady state inhalation methods, there was no difference in deposition pattern - that is, the distribution between the central and the peripheral lung zones - between the normal subjects and the patients with airways obstruction.

It is clear that the effect of most bronchodilator drugs released from pressurised metered dose inhalers is caused by only a small percentage of the active substance gaining entry to the airway system. Indirect studies based on pharmacokinetics suggest that about $10 \%$ of the inhaled dose enters the lungs.' Substituting Teflon particles radiolabelled with technetium-99m $\left({ }^{49 \mathrm{~m}} \mathrm{Tc}\right)$ for the active drug in a metered dose inhaler, Newman et al ${ }^{2}$ found that $8.8 \%$ of the particles entered the conducting airways and alveoli of patients with airways obstruction. Ideally, the results from such indirect methods should be compared with those obtained with bronchodilator drugs directly labelled with $\gamma$ emitting isotopes. This has always been a major technical problem since techniques for labelling bronchodilator drug complexes with $\gamma$ ray emitters are not readily available.

We have developed a method for labelling the anticholinergic bronchodilator ipratropium bromide

Address for reprint requests: Dr SG Spiro, University College Hospital, Gower Street, London WC1E 6AU.

Accepted 1 February 1984 with the $\gamma$ emitter bromine- $77\left({ }^{7} \mathrm{Br}\right)$. We give a brief outline of the technique and its quality control, followed by the results of drug deposition studies performed with a gamma camera in a group of normal subjects and patients with chronic bronchitis.

\section{Methods}

THE DRUG AND ITS ADMINISTRATION

The methods for labelling ipratropium bromide with ${ }^{77} \mathrm{Br}$ and incorporating it into a reconstituted metered dose aerosol have been described fully elsewhere. ${ }^{3}$ Briefly, we developed a system to label the drug, remill it into particles of the required size range, and add it to an accurately dispensed chlorofluorocarbon propellant mixture. Quality control procedures were also necessary to ensure compatibility with the commercial product. These procedures included ultraviolet colorimetry on canisters of both unlabelled and the labelled reconstituted drug and a final comparison of these was made with estimation of drug release based on loss of radioactivity. All reconstituted aerosols for clinical use were within the manufacturer's specification for the product. 
To obtain a statistically acceptable gamma camera image each subject was required to take 10 inhalations from the metered dose inhaler. The method of administration adopted was the one used móst commonly in clinical practice. After exhalation to residual volume, the inhaler was actuated while the subject began a fast, deep inhalation, with the lips around the plastic mouthpiece, to total lung capacity; the breath was held for five seconds. Expired air was collected in a Douglas bag. The subject was allowed to inhale at his preferred flow rate and frequency but the procedure was completed within four minutes. After inhalation, the subject gargled and spat out the mouthful of water, which was collected for counting the radioactivity, and then swallowed two further mouthfuls of water to clear the oesophagus of radioactivity. Radioactivity deposited on the actuator was also counted.

\section{IMAGING}

The subject was seated in front of the gamma camera so that the lung field was central within the field of view. Both anteroposterior and posteroanterior ${ }^{77} \mathrm{Br}$ images were obtained to permit subsequent quantitation of regional lung deposition, a geometric mean calculation being used. In vivo calibration factors to calculate this regional deposition were obtained on the basis of ${ }^{77} \mathrm{Br}$ activities in variable thickness tissue equivalent (water) phantoms. This related the count rate from the canister in air at a fixed distance from the camera to the equivalent count rate in a given thickness of tissue. Each subject's chest thickness was measured to effect this correction. Data were recorded into a $64 \times 64$ computer matrix with an imposed count limit of $50 \mathrm{~K}$ for the anteroposterior view. This number of counts was considered to be statistically acceptable for quantitation and the accumulation time short enough to avoid significant changes in the tracer distribution. The posteroanterior image was recorded for the same time as the anteroposterior image. After each ${ }^{77} \mathrm{Br}$ image and without moving the patient, a rapid transmission scan was obtained, a cobalt-57 $\left({ }^{57} \mathrm{Co}\right)$ flood field source being used. This gave an outline of the lungs and enabled an arbitrary division into a "peripheral zone" comprising the lateral two thirds of each lung and a "central zone." The region between the lungs was designated the "mediastinal zone" and comprised trachea, main bronchi, and oesophagus. Finally, a background image was accumulated for the same length of time so that lung regions selected for analysis could be corrected for background radioactivity.

\section{SUBJECTS}

Two groups of subjects were studied, seven normal
Table 1 Details of the normal subjects and patients with chronic bronchitis (means with standard deviations in parentheses)

\begin{tabular}{lcc}
\hline & Normal subjects & Patients \\
\hline Number & 7 & 7 \\
Age (y) & $29 \cdot 7(5 \cdot 3)$ & $50(21 \cdot 7)$ \\
FEV (\% predicted) & $106(12 \cdot 8)$ & $32(12 \cdot 2)$ \\
FVC (\% predicted) & $116(9 \cdot 7)$ & $54(12 \cdot 9)$ \\
PEFR (\% predicted) & $123(27)$ & $40(6 \cdot 9)$ \\
$\hat{V}_{\text {so }}$ (\% predicted) & $68(16)$ & $9(7 \cdot 5)$ \\
\hline
\end{tabular}

FEV - forced expiratory volume in one second; FVC - forced vital capacity; PEFR-peak expiratory flow rate; $\dot{\mathrm{V}}_{\text {so }}$-maximal expiratory flow at $50 \%$ of vital capacity.

Table 2 Fate of 10 puffs of ipratropium bromide in normal subjects and patients with chronic bronchitis (means with standard deviations in parentheses)

\begin{tabular}{lll}
\hline & Normal subjects & Patients \\
\hline Total dose inhaled $(\mu \mathrm{g})$ & $203(16 \cdot 9)$ & $186(22 \cdot 6)$ \\
Mouthwash $(\mu \mathrm{g})$ & $78(37.4)$ & $87(27)$ \\
Stomach $(\mu \mathrm{g})$ & $102(37)$ & $77(18 \cdot 8)$ \\
Lung dose $(\mu \mathrm{g})$ & $22.7(7.6)$ & $21.8(10 \cdot 6)$ \\
Lung dose $(\%)$ & $11.2(4 \cdot 0)$ & $11.7(6.4)$ \\
\hline
\end{tabular}

and seven with chronic obstructive bronchitis. Pulmonary function studies before the start of the inhalation procedures were performed with a dry bellows spirometer with a microprocessor output (Oldelft "Floop") and included the forced expiratory volume in one second $\left(\mathrm{FEV}_{1}\right)$, forced vital capacity (FVC), peak expiratory flow rate (PEFR), and maximal expiratory flow at $50 \%$ of vital capacity $\left(\dot{\mathrm{V}}_{50}\right)$. Predicted normal values were taken from Cotes. ${ }^{4}$

\section{Results}

The personal details of the two groups are summarised in table 1 . The patients were older than the normal subjects and had moderately severe airways obstruction.

The fate of 10 puffs of ipratropium bromide is summarised in table 2. The mean total doses inhaled were similar in the two groups and close to $200 \mu \mathrm{g}$. An additional $5 \%$ of the drug released from the canister remained in the actuator. The distribution of ipratropium bromide was also similar in the two

Table 3 Distribution of 10 puffs of ipratropium bromide within the lungs of normal subjects and patients with chronic bronchitis (means with standard deviations in parentheses)

\begin{tabular}{|c|c|c|c|c|c|}
\hline & & \multicolumn{2}{|c|}{ Normal subjects } & \multicolumn{2}{|l|}{ Patients } \\
\hline & & $\mu g$ & $\begin{array}{l}\% \text { total } \\
\text { lung dose }\end{array}$ & $\mu g$ & $\begin{array}{l}\text { \% total } \\
\text { lung dose }\end{array}$ \\
\hline \multirow{3}{*}{$\begin{array}{l}\text { Peripheral } \\
\text { lung zone } \\
\text { Central lung } \\
\text { zone } \\
\text { Mediastinal } \\
\text { zone }\end{array}$} & \multirow{3}{*}{$\begin{array}{l}\mathbf{R} \\
\mathbf{L} \\
\mathbf{R} \\
\mathbf{L}\end{array}$} & $\begin{array}{l}5 \cdot 6(2.3) \\
5.6(2.3)\end{array}$ & $49 \cdot 3$ & $\begin{array}{l}5.6(2.9) \\
4.8 \\
(2.6)\end{array}$ & $47 \cdot 7$ \\
\hline & & $\begin{array}{l}3.6(1.6) \\
3.2(1.4)\end{array}$ & 30.0 & $\begin{array}{l}2.8(1.7) \\
2.9(1.4)\end{array}$ & $26 \cdot 1$ \\
\hline & & $4.6(1.9)$ & $20 \cdot 3$ & $5.6(2.6)$ & $25 \cdot 7$ \\
\hline
\end{tabular}


Table 4 Distribution of 10 puffs of ipratropium bromide per unit lung area in normal subjects and patients with chronic bronchitis (means with standard deviations in parentheses)

\begin{tabular}{|c|c|c|}
\hline & Normal subjects & Patients \\
\hline $\begin{array}{l}\text { Peripheral lung zone (\%) } \\
\text { Central lung zone }(\%) \\
\text { Mediastinal zone }(\%)\end{array}$ & $\left.\begin{array}{l}28 \cdot 6(2 \cdot 3) \\
33 \cdot 7(2 \cdot 7) \\
37.7(4 \cdot 5)\end{array}\right\} 71 \cdot 4$ & $\left.\begin{array}{l}28 \cdot 5(1 \cdot 8) \\
33 \cdot 3(4 \cdot 8) \\
38 \cdot 2(4 \cdot 3)\end{array}\right\} 71 \cdot 5$ \\
\hline
\end{tabular}

groups; most of the drug was either deposited in th̀e mouth or swallowed- $180 \mu \mathrm{g}$ in the normal subjects and $164 \mu \mathrm{g}$ in the patients. The mean dose reaching the lung (including the mediastinal zone) was $11.2 \%$ and $11.7 \%$ respectively.

The distribution of the $22.7 \mu \mathrm{g}$ of ipratropium bromide deposited in the lungs of the normal subjects and the $21.8 \mu \mathrm{g}$ in the lungs of the patients is summarised in table 3 . There was no significant difference between the normal subjects and the patients. Correction for area (since the peripheral zone occupied two thirds of the total lung area) made the distribution more even (table 4 ), $28 \%$ of the lung dose being deposited in the peripheral zone, $33 \%$ in the central zone, and $38 \%$ in the mediastinal zone.

\section{Discussion}

An accurate and reproducible technique for labelling ipratropium bromide in a metered dose inhaler has been described. Since gamma camera imaging was carried out within a few minutes of completion of the 10 inhalations of ipratropium bromide, it was assumed that the ${ }^{17} \mathrm{Br}$ label had remained in association with the drug complex. Since ipratropium bromide is soluble in water it is likely to go into solution rapidly, but little change in its initial deposition pattern was evident during the first few minutes after inhalation.

Aerosol deposition within the thorax has usually been calculated by arbitrary division of the two dimensional images obtained into zones that could be interpreted anatomically, and techniques of varying complexity have been used. Dolovich et $a^{5}$ divided one lung into 125 elements and then produced three cresentic zones, between which clear differences in deposition were observed in the presence of increasing airways obstruction, showing preferential central deposition. Simpler methods confine measurements to the mediastinum (tracheobronchial zone) and the lung alveoli, the two zones being distinguished by observing the residual activity at 24 hours, which is assumed to represent alveolar deposition. ${ }^{2}$ We have attempted to measure three zones by dividing the lung into a central third and a peripheral two thirds in addition to the midline mediastinal zone. Owing to uncertainty about how long ${ }^{\mathrm{B}} \mathrm{Br}$ remains bound to ipratropium bromide, however, it was not possible to measure alveolar deposition 24 hours after inhalation. Our peripheral zone therefore is assumed to contain drug deposited in airways as well as in alveoli.

Studies comparing normal subjects with individuals suffering from lung disease have used a "steady state" tidal breathing technique with inhalation of monodispersed labelled particles generated within a chamber by means of a spinning disc. These techniques have shown that normal and abnormal subjects have different deposition patterns, increasingly severe airways obstruction being associated with increasingly central deposition. ${ }^{56}$ Data on aerosol deposition from a metered dose inhaler are limited and confined to patients with airways obstruction. ${ }^{278}$ The data presented here on patients with airways obstruction using a metered dose inhaler have shown the total thorax deposition to be almost identical to that in the normal group. Comparative data are scanty. In eight patients with airways obstruction, $66 \%$ of the $8.8 \%$ of Teflon particles entering the thorax from a metered dose inhaler entered the tracheobronchial zone and $34 \%$ the alveoli. ${ }^{2}$ Recently Newman et $a l^{9}$ showed that deposition of aerosol from a metered dose inhaler was unaffected by either particle size or FEV (range $27-120 \%$ predicted normal), $70 \%$ of the thoracic dose being centrally deposited. Our data appear to be similar since, after correction for lung area, $70 \%$ of the inhaled dose was deposited in the two most central zones (table 4). It would appear that aerosol deposition from a metered dose inhaler differs from steady state inhalation and that it is less affected by airways obstruction.

The cause of this difference is not certain. Probably the predominantly central deposition is due to the high ejection velocity of the drug and also the proximity of the metered dose inhaler to the mouth, which does not allow time for sufficient decrease in size by evaporation of the chlorofluorocarbon pellets released at actuation. This may explain why intrathoracic deposition is increased with a tube device or a spacer attachment, ${ }^{78}$ so that lung function is better than when the metered dose inhaler is used alone. ${ }^{10}$ In the study of Newman et al 10 patients with airways obstruction had a mean whole lung deposition of $7.8 \%$ of inhaled Teflon labelled particles, which increased to $13.0 \%$ when a $22 \mathrm{~cm}$ long spacer cone was used.

We have shown that pharmacokinetic methods and indirect methods of estimating the dose of aerosol entering the lungs ${ }^{2}$ from a metered dose inhaler are sufficiently accurate. For direct labelling 
of a bronchodilator drug with $\gamma$ emitting radionuclides the bronchodilator must have a suitable radical for binding. At present this property would appear to be confined to ipratropium bromide and possibly fenoterol.

We wish to thank Mr W Kirk of Riker Laboratories and Mr T Simcock and Mr S Kelly of ICI Mond Division for providing invaluable advice and assistance and Miss A Betchley for typing the manuscript. The Medical Research Council Cyclotron Unit at Hammersmith Hospital, London, provided ${ }^{77} \mathrm{Br}$ and Boehringer Ingelheim Ltd provided technical data and financial support.

\section{References}

' Davies DS. Pharmacokinetics of inhaled substances. Postgrad Med J 1975;51, suppl 7: 69-75.

${ }^{2}$ Newman SP, Pavia D, Moren F, Sheahan NF, Clarke SW. Deposition of pressurized aerosols in the human respiratory tract. Thorax $1981 ; 36: 52-5$.

${ }^{3}$ Short MD, Singh CA, Few JD, Studdy PR, Heaf PJD,
Spiro SG. The labelling and monitoring of lung deposition of an inhaled synthetic anticholinergic bronchodilating agent. Chest $1981 ; 80$ : $918-21$.

${ }^{4}$ Cotes JE. Lung function: assessment and application in medicine. Oxford: Blackwell Scientific Publications, 1979.

${ }^{5}$ Dolovich MB, Sanchis J, Rossman C, Newhouse MT. Aerosol penetrance: a sensitive index of peripheral airways obstruction. J Appl Physiol 1976;40:468-71.

- Goldberg IS, Lourenco RV. Deposition of aerosols in pulmonary disease. Arch Intern Med 1973;131:83-91.

${ }^{7}$ Newman SP, Moren F, Pavia D, Little F, Clarke SW. Deposition of pressurized suspension aerosols inhaled through extension devices. Am Rev Respir Dis 1981;124:317-20.

${ }^{8}$ Newman SP, Pavia D, Clarke SW. How should a pressurized $\beta$-adrenergic bronchodilator be inhaled? Eur $J$ Respir Dis 1981;63:3-21.

${ }^{9}$ Newman SP, Killip M, Pavia D, Moren F, Clarke SW. Do particle size and airway obstruction affect the deposition of pressurized inhalation aerosols? Thorax 1983;38:233 (abstract).

${ }^{10}$ Lindgren SB, Formgren H, Moren F. Improved aerosol therapy of asthma: effect of actuater tube size on drug availability. Eur J Respir Dis 1980;61:56-61. 